\title{
A CONCEPTUAL STUDY OF A LIQUID METAL ALLOY IN A DISK-SHAPED MAGNETOHYDRODYNAMICS CONVERSION SYSTEM
}

\author{
Ayokunle O. Ayeleso*, Atanda K. Raji \\ Cape Peninsula University of Technology, Electrical, Electronic \& Computer Engineering, Bellville 7535, \\ PO Box 1906, Cape Town, South Africa \\ * corresponding author: kulama2005@gmail.com
}

\begin{abstract}
The use of solar-heated liquid metal in a magnetohydrodynamics (MHD) generator provides an alternative and direct conversion method for electric power generation. This prompted the present study to conduct a three-dimensional numerical analysis for a liquid $\mathrm{Ga}_{68} \mathrm{In}_{20} \mathrm{Sn}_{12}$ flow exposed to several uniform magnetic field intensities $\left(B_{o}\right.$ of $0.5 \mathrm{~T}, 1 \mathrm{~T}$ and, $\left.1.41 \mathrm{~T}\right)$ within a disk channel geometric boundary. The aim is to study the influence of the external magnetic fields on the generator performance and the fluid flow stability at a high Reynolds number $\left(R_{e}\right)$ and Hartmann number $\left(H_{a}\right)$ using the Ansys Fluent software. The simulation results show that at $R_{e}$ of $\approx 2.44 e 6$, the fluid velocity decreases inside the generator regardless of $B_{o}$. When $B_{o}$ of $1 \mathrm{~T}$ and $1.41 \mathrm{~T}$ are applied, the velocity magnitude decreases and spreads within the disk channel and walls due to high Ha values (5874 and 8282). The fluid pressure increases from the nozzle pipe inlet to the disk channel and decreases towards the outlet. The induced current density in the radial direction, $j_{x}$, increases within the disk channel and near the inner electrode edge as $B_{o}$ increases. A significant observation is that the current densities obtained for $B_{o}$ of $1 \mathrm{~T}$ and $1.41 \mathrm{~T}$ cases are higher than in other cases. The numerical analysis obtained in this study showed that the $B_{o}$ of either $1 \mathrm{~T}$ or $1.41 \mathrm{~T}$ is needed to achieve the required flow stability, current density, and output powers.
\end{abstract}

KEYworDs: Solar, liquid metal, disk MHD generator, magnetic field, current density.

\section{INTRODUCTION}

In the past decades, electrically conducting fluid such as liquid metal under externally applied magnetic field has become the subject of various engineering and industrial applications. These applications include nuclear reactor cooling, liquid metal flow control, nanofluid flow in thermal and energy systems, high-temperature plasma, mini and micro magnetohydrodynamics (MHD) pumps, and MHD power generators [1 9].

Mebarek-Oudina et al. [1] investigated the stability of natural convection in an inclined cylindrical annulus ring containing molten potassium under the influence of a radial magnetism and a small number of Prandtl liquids $\left(P_{r}=0.072\right)$. They found that the best stabilization of the natural oscillatory convection occurred with the strongest magnetic field, the high radii ratio, and the inclination of the annulus for $\gamma=30^{\circ}$. The angle of inclination and radii ratio of the annulus have a significant effect on magneto-convective flux stabilization. Teimouri et al. 10] also investigated the natural convection of molten potassium in a long horizontal ring under the influence of radial magnetism. Their results showed that increasing the radii ratio reduces the magnetic field influence on the natural convection. In another study, Afrand et al. [11] examined the flow in an inclined cylindrical ring containing molten potassium under the influence of magnetism. Their results showed that the average Nusselt number decreased with increasing Hartmann number, $H_{a}$, when the magnetic field was perpendicular to the ring axis. Yadav et al. [12] investigated the influence of the $H_{a}$ and Brinkman number on the MHD convection flow of a viscous fluid between two horizontal concentric cylinders. They found that with increasing Ha values, there is a reduction in fluid velocity and irreversibility ratio. In other research, Zhang et al. [13] experimentally investigated the liquid Galinstan (Ga $68 \%$, In $20 \%$, and Sn $12 \%$ ) based mini channel cooling for high heat flux thermal devices. Their results showed that liquid Galinstan driven by a high-efficiency direct current electromagnetic pump (DC-EMP) dissipate heat with a heat flux of $300 \mathrm{~W} / \mathrm{cm}^{2}$, heat power of $1500 \mathrm{~W}$, and a pressure of $100 \mathrm{kPa}$. Taheri et al. 14] use a numerical finite volume method (FVM) and artificial neural network (ANN) to compute the flow at the entrance length of a laminar MHD rectangular channel at different values of the Reynolds numbers, $R_{e},(600<R e<1100)$ and $H_{a}(4<H a<10)$. They obtained results for various physical parameters and found that Ha increases the Lorentz force while decreasing the velocity profile and the MHD entrance length.

To our knowledge, there is still no published study that has investigated the influence of axial magnetism on the flow of liquid Galinstan in a disk channel at a high $R_{e}$ and $H_{a}$. Therefore, the present study aims to 


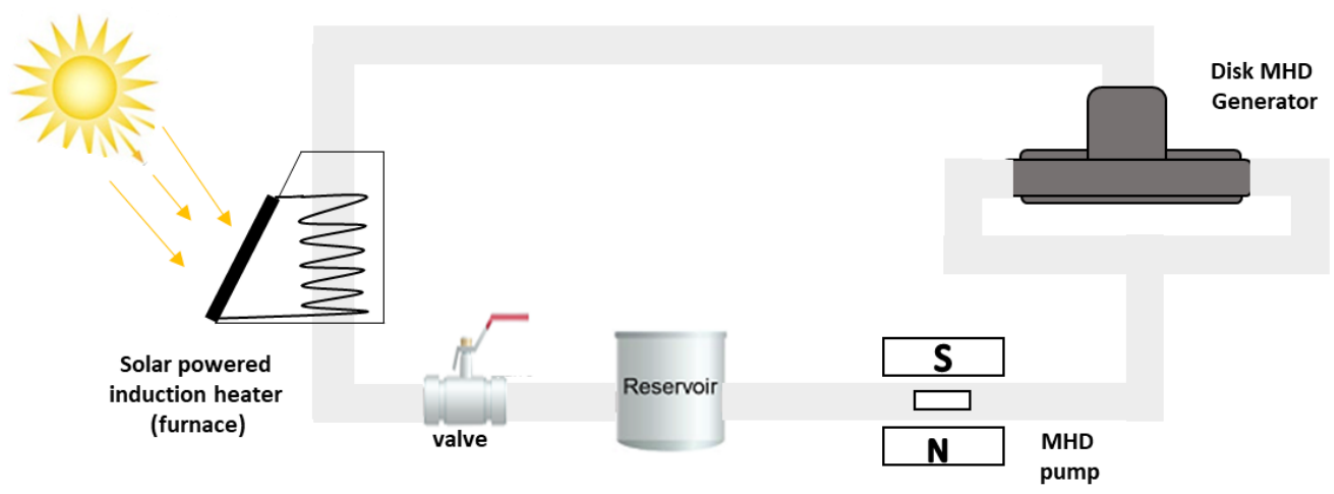

Figure 1. The liquid $\mathrm{Ga}_{68} \mathrm{In}_{20} \mathrm{Sn}_{12}$ flow cycle.

conduct a computational analysis for the flow of liquid $\mathrm{Ga}_{68} \mathrm{In}_{20} \mathrm{Sn}_{12}$ in a disk channel under the influence of several external magnetic fields, $B_{o}: 0 \mathrm{~T}, 0.5 \mathrm{~T}, 1 \mathrm{~T}$, and $1.41 \mathrm{~T}$. The study also investigates the effects of high $R_{e}$ and $H_{a}$ on the flow stability and generator performance in the low Prandtl number fluid $\left(P_{r}=\right.$ 0.028) and steady-state conditions using the Ansys Fluent software.

\section{THEORETICAL BACKGROUND}

\subsection{Liquid Galinstan Flow CyCle}

The fluid considered in this study is liquid Galinstan $\left(\mathrm{Ga}_{68} \mathrm{In}_{20} \mathrm{Sn}_{12}\right)$. It is a non-toxic, non-radioactive, low melting point $\left(-19^{\circ} \mathrm{C}\right)$, high thermal conductivity, and chemically stable fluid $15-18$. This fluid does not stick to superlyophobic structured surfaces and behaves like a liquid in an environment with oxygen levels below 1 part per million (ppm) [16, 17]. Furthermore, liquid $\mathrm{Ga}_{68} \mathrm{In}_{20} \mathrm{Sn}_{12}$ does not have wettability issues in channels and pipes developed with materials like Plexiglas, Teflon, Organic materials, Tungsten, Silicon tubes, Nickel, PVC, and Glass [18. Fig. 11 depicts the schematic diagram of the liquid $\mathrm{Ga}_{68} \mathrm{In}_{20} \mathrm{Sn}_{12}$ flow cycle. In this figure, the fluid flows out of the reservoir through a valve and is pre-heated by a solar heater before entering the disk MHD generator. Subsequently, the fluid exiting the generator is recycled back through an electromagnetic pump at a pressure head of $100 \mathrm{kPa}$ for the next round of circulation.

\subsection{Disk MHD Generator GeOMEtry AND MATERIAL PROPERTIES}

Fig. 2 depicts the geometry of the disk MHD generator considered in the present study. In this figure, the fluid flows through the nozzle pipe inlet into the disk channel in the axial direction (z-axis) and then towards the outlet in the radial direction (x-axis). The diameter of the nozzle pipe inlet is $66.03 \mathrm{~mm}$. The disk channel diameter is $152.12 \mathrm{~mm}$, and the height of the outlet is $37.9 \mathrm{~mm}$. Furthermore, there are two circular tungsten copper electrodes in the y-axis direction perpendicular to the direction of $B_{o}$.

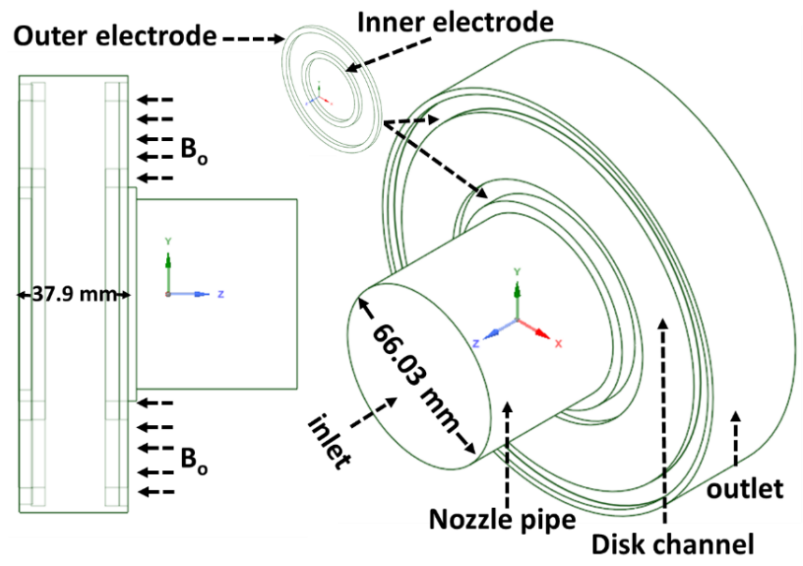

Figure 2. The disk MHD generator.

\subsection{GOVERNING EQUATIONS}

The present study considered the turbulence flow of a viscous, incompressible, and electrically conducting fluid in magnetic fields. The governing equations are mass conservative (continuity), Navier-Stokes momentum, and Ohm's law 19,

$$
\begin{gathered}
\nabla \times v=0 \\
\rho\left(\frac{\partial v}{\partial t}+(v \cdot \nabla) v\right)=\rho+\eta \nabla^{2} v-\nabla P+j \times \mathrm{B}
\end{gathered}
$$

where $\rho$ is the density, $P$ is the pressure, $v$ is the velocity, $\eta$ is the viscosity, $\mathrm{B}=\mathrm{B}_{0}+\mathrm{b}$ is magnetic flux density, $\mathrm{B}_{0}$ is the external magnetic field, $\mathrm{b}$ is the induced magnetic field produced by the motion of the fluid through $\mathrm{B}_{0}$.

The current density, $j$, expression is given by [14],

$$
j=\sigma(E+v \times \mathrm{B})
$$

In a generalized form, the Ohm's law equation in Equation 3 can be re-written as [9],

$$
j+\frac{\beta}{|\mathrm{B}|} j \times \mathrm{B}=\sigma(E+v \times \mathrm{B})
$$

where $E$ is the electric field, $\sigma$ is the electrical conductivity, $\beta=e \mathrm{~B} / m_{e} v_{e h}$ is the hall parameter, $e$ is the electron charge, $m_{e}$ is the electron mass and $v_{e h}$ 


\begin{tabular}{lll}
\hline \multirow{4}{*}{ General setup } & Solver Type & Density-Based \\
& 3D Space & Planar \\
& Time & Steady \\
& Velocity formulation & Absolute. \\
\hline \multirow{3}{*}{ Models } & Energy equation & On \\
& Viscous model & Standard k-epsilon model \\
& & Standard Wall Function. \\
\hline \multirow{4}{*}{ Models } & Fluid & $\mathrm{Ga}_{68} \mathrm{In}_{20} \mathrm{Sn}_{12}$ \\
& Melting point & $10.8{ }^{\circ} \mathrm{C}$ \\
& Density & $6363.2 \mathrm{~kg} / \mathrm{m}^{3}$ \\
& Dynamic viscosity & $0.00222 \mathrm{~kg} /(\mathrm{m} \cdot \mathrm{s})$ \\
& Thermal conductivity & $26.72 \mathrm{~W} /(\mathrm{m} \cdot \mathrm{K})$ \\
& Specific heat & $331 \mathrm{~J} /(\mathrm{kg} \cdot \mathrm{K})$ \\
& Magnetic permeability & $8 \mathrm{e}-7 \mathrm{~h} / \mathrm{m}$ \\
& Electrical conductivity & $3.31 \mathrm{e} 6 \mathrm{~s} / \mathrm{m}$ \\
& Kinematic viscosity, $\nu$ & $3.49 \mathrm{e}-7 \mathrm{~m}{ }^{2} / \mathrm{s}$ \\
& Thermal diffusivity, $\alpha$ & $1.27 \mathrm{e}-5 \mathrm{Wm}{ }^{2} / \mathrm{J}$ \\
\hline Cell boundary zone & Fluid Domain & \\
\hline & Inlet & Velocity-Inlet \\
& Velocity & $5.606311 \mathrm{~m} / \mathrm{s}$ \\
& Outlet & Pressure-Outlet \\
Boundary conditions & Gauge Total Pressure & $1 \mathrm{e} 5 \mathrm{~Pa}$ \\
& Inlet Temperature & $323 \mathrm{~K}=49.85{ }^{\circ} \mathrm{C}$ \\
& Outlet Temperature & $300 \mathrm{~K}$ \\
\hline & &
\end{tabular}

TABLE 1. Setup and boundary conditions.

is the average momentum transfer collision frequency for an electron (e) with a heavy particle (h).

Taking the curl of $E$ in Equation 3 gives,

$$
\nabla \times E=-\nabla \times\left(\frac{j}{\sigma}\right)+\nabla \times(v \times \mathrm{B})
$$

By neglecting the displacement current from Maxwell's equation $(\nabla \times H=j+\partial D / \partial t)$, the remaining expression gives $\nabla \times H=j$. Substituting the Maxwell's induction field $\left(H=\mathrm{B} / \mu_{m}\right)$ into $\nabla \times H=j$, the induced current density becomes [20],

$$
j=\frac{\nabla \times \mathrm{B}}{\mu_{m}}
$$

Inserting Equation 6 into Equation 5 and using the following properties, $\nabla \times \mathrm{B}, \nabla \times E=\partial \mathrm{B} / \partial t$ $\nabla \times(\nabla \times \mathrm{B})=\nabla(\nabla \cdot \mathrm{B})-\mathrm{B}(\nabla \cdot \nabla)$, the magnetic induction equation is derived as [21, 23],

$$
\frac{\partial \mathrm{B}}{\partial t}+(v \cdot \nabla) \mathrm{B}=\frac{1}{\mu_{m} \sigma} \nabla^{2} \mathrm{~B}+(\nabla \cdot \mathrm{B}) v
$$

where $\mu_{m}$ is the magnetic permeability.

\section{The THREE-DIMENSIONAL MODELLING OF THE DISK MHD GENERATOR}

The physical and thermodynamic properties considered in the simulation of the liquid Ga68In20Sn12 are mainly the density, electrical conductivity, viscosity, and magnetic permeability. Table1 1 presents the setup and boundary conditions considered for this study.

The boundary conditions in Table 1 are chosen based on the physical and thermal properties of liquid $\mathrm{Ga}_{68} \mathrm{In}_{20} \mathrm{Sn}_{12}$. The disk channel boundary condition is a no-slip wall boundary, which means that the radial velocity, $v_{r}$, and tangential velocity, $v_{q}$, are equal to the wall velocity. A pressure-based solver is used to solve these boundary conditions. Furthermore, the pressure-velocity couplings are solved using the coupled scheme solution method. The pressure calculations are solved using the second-order upwind discretization. The first order upwind is chosen for the momentum, energy, and magnetic induction calculations. The external magnetic field is added as a volume force once the initial hydrodynamic solution is converged and completed.

\section{GRID INDEPENDENCE TEST}

The disk MHD generator geometry consists of nonuniform grids around the electrodes and walls. Thus, to reduce numerical errors in the simulation results, several grid sizes are investigated for a grid independence study. For this purpose, the grid systems of $84867 \times 75176,107354 \times 79613,159518 \times 89321$, $212249 \times 99106,260378 \times 107846,303372 \times 115539$, $358068 \times 125355,402795 \times 133596,441995 \times 140739$, and $509521 \times 152988$ are investigated for liquid $\mathrm{Ga}_{68} \mathrm{In}_{20} \mathrm{Sn}_{12}$ flow at $\mathrm{B}_{0}=0$ and $P_{r}=0.028$ (Ta- 


\begin{tabular}{cccc}
\hline Case & Element & Node & Velocity $(\mathrm{m} / \mathrm{s})$ \\
\hline 1 & 84867 & 75176 & 3.97 \\
2 & 107354 & 79613 & 3.95 \\
3 & 159518 & 89321 & 4.35 \\
4 & 212249 & 99106 & 4.50 \\
5 & 260378 & 107846 & 4.56 \\
6 & 303372 & 115539 & 4.61 \\
7 & 358068 & 125355 & 4.66 \\
8 & 402795 & 133596 & 4.67 \\
9 & 441995 & 140739 & 4.67 \\
10 & 509521 & 152988 & 4.68 \\
\hline
\end{tabular}

TABLE 2. Maximum velocity at the disk outlet for different grid resolutions.

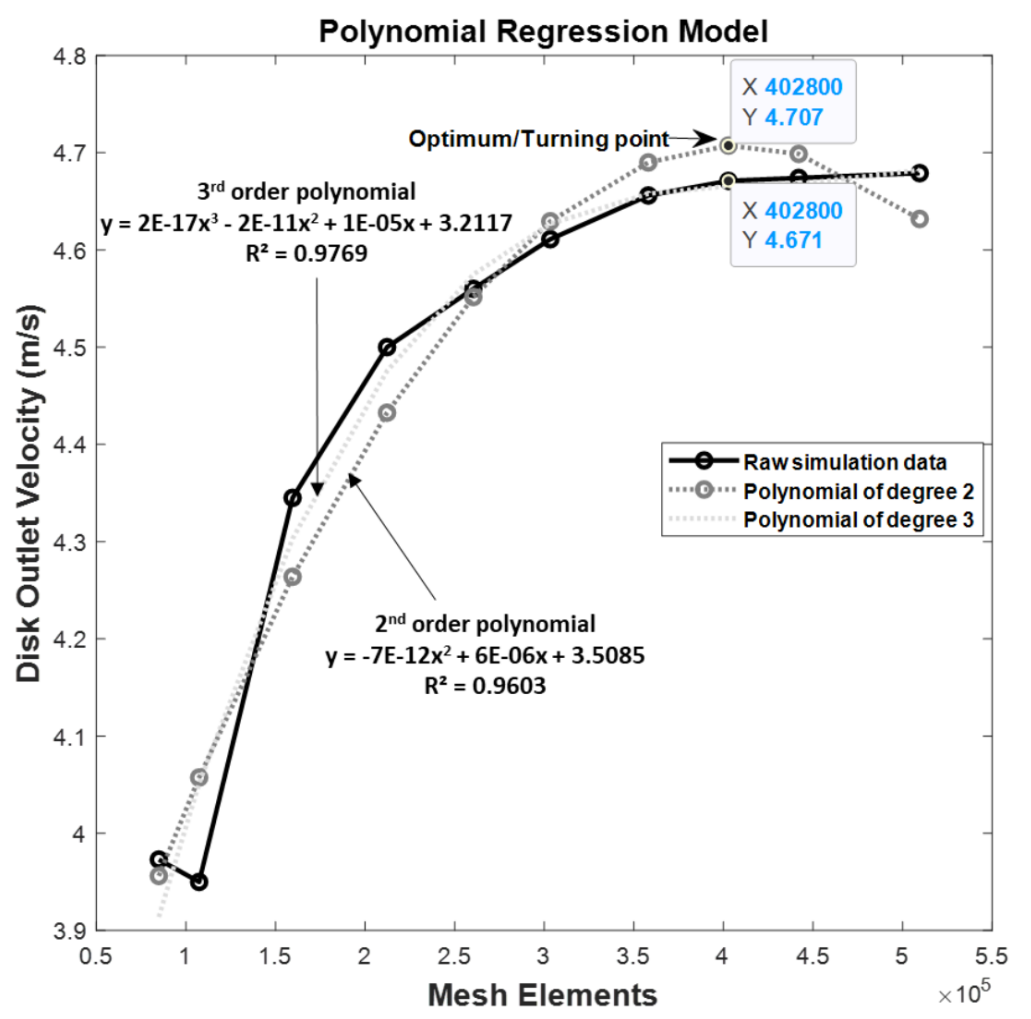

FiguRE 3. Profiles of the local outlet velocities with different mesh grid sizes.

ble 22). The maximum velocity at the disk outlet (probing point) serves as the control parameter. For the different grid sizes investigated, the flow field variables reach a fully developed state and then converge.

From Table 2 the maximum differences between $402795 \times 133596,441995 \times 140739$, and $509521 \times$ 152988 grid systems are within $0.01 \%$. The velocity results also showed that a change of less than $1 \%$ is observed in computed values when varying the grid sizes. Furthermore, to determine the exact turning point and optimum grid point at which the velocity results variation is no longer significant, a quadratic regression model is performed using the polynomial degree order of greater than one. This method creates the best-fitting curve alongside the initial velocity graph, as shown in Fig. 3
As seen from Fig. 3, the polynomial of degrees 3, with a coefficient of determination (r-square) of $98 \%$, produces the best fitting curve. Also, the polynomial of degree 2 , with an r-square of $96 \%$, clearly shows that the turning point occurs at $402795 \times 133596$ grid size. At this point, the numerical solution does not change significantly (i.e., independent) with varying mesh sizes. Therefore, the adopted mesh grid for all numerical simulations is a polyhedral dominant-shaped with 402795 elements and 133596 nodes (Fig. 4). The selected grid optimizes the CPU $(2.3 \mathrm{GHz})$ time and the cost of computations.

Based on the selected mesh grid size, the convergence criteria at a given time-step are declared when the iteration level of the residuals of $\mathrm{x}-, \mathrm{y}-$ and $\mathrm{z}-$ velocities, continuity, and k-epsilon fall below $10^{-3}$. Furthermore, the mass-weighted average of the veloc- 


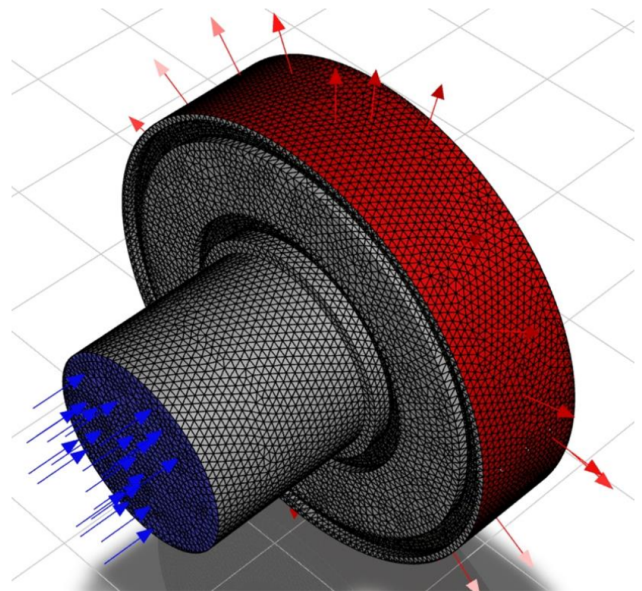

Figure 4. Mesh display of the disk MHD generator.

ity magnitude at the disk outlet under different $\mathrm{B}_{0}$ cases in Fig. 5 gives a further insight into the solution convergence. The result of the first simulation without magnetic fields $\left(\mathrm{B}_{0}=0 \mathrm{~T}\right)$ shows that the velocity solution converges at a steady value of $3.13 \mathrm{~m} / \mathrm{s}$. Subsequently, by applying the $\mathrm{B}_{0}$ values of $0.5 \mathrm{~T}, 1 \mathrm{~T}$, and $1.41 \mathrm{~T}$ to the initial solution, the velocity magnitude reaches a steady state with convergence values of $1.64 \mathrm{~m} / \mathrm{s}, 1.43 \mathrm{~m} / \mathrm{s}$, and $1.32 \mathrm{~m} / \mathrm{s}$, respectively.

\section{Disk MHD Generator MODELLing RESULTS}

This section discusses the effect of the $R_{e}, H_{a}$, and interaction parameter, $N$, on the fluid velocity, pressure gradient, and current density for different values of $\mathrm{B}_{0}$.

\subsection{Magnetic Flux Density}

Fig. 6 presents the plot of the magnetic flux density along the nozzle pipe and disk channel. The flux density in Fig. 6a increases from the nozzle pipe inlet $(z=0.044 \mathrm{~m})$ and reaches optimum at about $(z=-0.024 \mathrm{~m})$ and then slightly decreases at the disk channel centre. From the disk centre $(x=0.0007 \mathrm{~m}$, $y=0, z=-0.032 \mathrm{~m}$ ), the flux decreases towards the outlet, as shown in Fig. 6b. The maximum magnetic flux density of $0.034 \mathrm{~T}, 0.065 \mathrm{~T}$, and $0.088 \mathrm{~T}$ are obtained along the disk centre when the $\mathrm{B}_{0}$ values of $0.5 \mathrm{~T}, 1 \mathrm{~T}$, and $1.41 \mathrm{~T}$ are applied (Fig. 6b). The above results show that the $\mathrm{B}_{0}$ value of either $1 \mathrm{~T}$ or $1.41 \mathrm{~T}$ is sufficient to decelerate the fluid flow inside the disk channel geometry considered in this study.

\subsection{Velocity distribution}

Figs. 7 and 8 show the contour $(x-z$ plane, $y=0)$ and plot of velocity magnitude along the nozzle pipe and disk channel. The velocity distribution changes as the $\mathrm{B}_{0}$ value gradually increases from 0 to $1.41 \mathrm{~T}$. In the case where there is no magnetic field (equivalent to $H_{a}=0$ ), the fluid moves from the nozzle pipe and gradually decelerates as it reaches the disk channel (Fig. 8a). The velocity of $5.606 \mathrm{~m} / \mathrm{s}$ at the nozzle pipe inlet $(z=0.044 \mathrm{~m})$ decelerates to about $2.717 \mathrm{~m} / \mathrm{s}$ at the disk centre. From the disk centre $(x=0.0007 \mathrm{~m}, y=0, z=-0.032 \mathrm{~m})$, the velocity decreases towards the outlet and forms an M-shaped profile in the radial direction (Fig. 8b). When the $\mathrm{B}_{0}$ values of $0 \mathrm{~T}, 0.5 \mathrm{~T}, 1 \mathrm{~T}$, and $1.41 \mathrm{~T}$ (i.e., $H_{a}$ of 2937, 5874, and 8282) are applied, the maximum velocities obtained are $4.943 \mathrm{~m} / \mathrm{s}(x=-0.036 \mathrm{~m})$, $4.331 \mathrm{~m} / \mathrm{s}(x=0.038 \mathrm{~m}), 3.283 \mathrm{~m} / \mathrm{s}(x=-0.038 \mathrm{~m})$, and $3.166 \mathrm{~m} / \mathrm{s}(x=-0.033 \mathrm{~m})$, respectively. Moreover, we can see in Fig. 7 that for $\mathrm{B}_{0}$ values of $1 \mathrm{~T}$ and $1.41 \mathrm{~T}\left(H_{a}=5874\right.$ and $\left.H_{a}=8282\right)$, the decelerated fluid spreads rapidly within the disk and the velocity near the conducting walls increases. In general, the velocity at the disk centre is higher than at the sidewalls. These observations fully agree with the findings reported by [14, 24, 25].

\subsection{Pressure GRAdiEnT}

The plot in Fig. 9a presents the pressure gradient along the nozzle pipe. In this figure, the pressure behaviour showed that the magnetic force has almost no effect on the fluid velocity in the axial direction ( $z$-axis). In addition to this, an elevated pressure is noticeable from the nozzle pipe inlet $(z=0.044 \mathrm{~m})$ to the disk centre $(x=0.0007 \mathrm{~m}, y=0, z=-0.032 \mathrm{~m})$. Hence, we can deduce that the imposed disk inlet and outlet geometries are the essential parameters responsible for the pressure elevation. Conversely, from the centre of the disk, the pressure decreases towards the outlet, as shown in Fig. 9b Similar outcomes have been reported by [26] using a rectangular channel. In the outlet of the disk channel $(x=-0.076 \mathrm{~m}, x=0.076 \mathrm{~m})$, the pressure obtained is approximately $100 \mathrm{kPa}$. This pressure exits the disk channel outlet and activates the electromagnetic pump in Fig. 1 for the next round of circulation.

\subsection{Current Density}

The plot and contour in Figs. 10 and 11 present the induced current density along the inner and outer electrode regions. As shown previously in Fig. 2, the magnetic force is in the axial ( $z$-axis) direction and the conductive fluid flow traversing the magnetic force is in the radial ( $x$-axis) direction. The effect of the retarding Lorentz force on the current density in the radial direction, $j_{x}$, can be seen in Fig. 11 for the different $\mathrm{B}_{0}$ and $H_{a}$ cases. When $\mathrm{B}_{0}$ values of $0.5 \mathrm{~T}, 1 \mathrm{~T}$, and $1.41 \mathrm{~T}$ are applied, the maximum $j_{x}$ values obtained near the inner electrode $(x=-0.04072 \mathrm{~m}, x=0.04072 \mathrm{~m})$ are $1.03 \mathrm{e} 6 \mathrm{~A} / \mathrm{m}^{2}, 2.89 \mathrm{e} 6 \mathrm{~A} / \mathrm{m}^{2}$, and $3.79 \mathrm{e} 6 \mathrm{~A} / \mathrm{m}^{2}$, respectively. Whereas the maximum $j_{x}$ values obtained near the outer electrode $(x=-0.07145 \mathrm{~m}, x=0.07145 \mathrm{~m})$ are $8.79 \mathrm{e} 5 \mathrm{~A} / \mathrm{m}^{2}, 5.49 \mathrm{e} 5 \mathrm{~A} / \mathrm{m}^{2}$, and $1.15 \mathrm{e} 6 \mathrm{~A} / \mathrm{m}^{2}$, respectively. Moreover, we can see in Fig. 11 that as $\mathrm{B}_{0}$ and $H_{a}$ increase, the current density increases near the inner electrode edge and gradually decreases toward the disk outlet. For the cases where the $\mathrm{B}_{0}$ values 

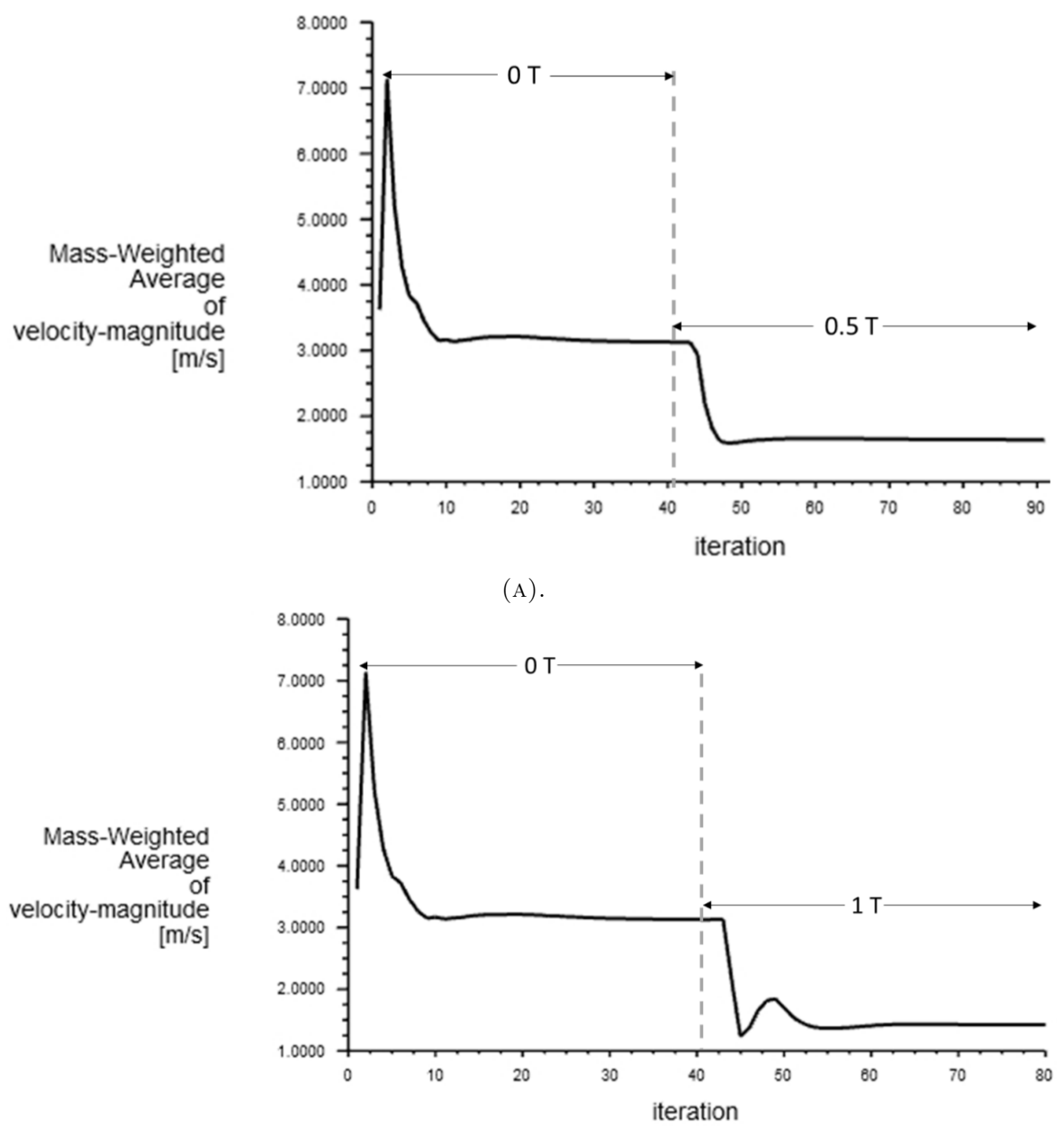

(в).

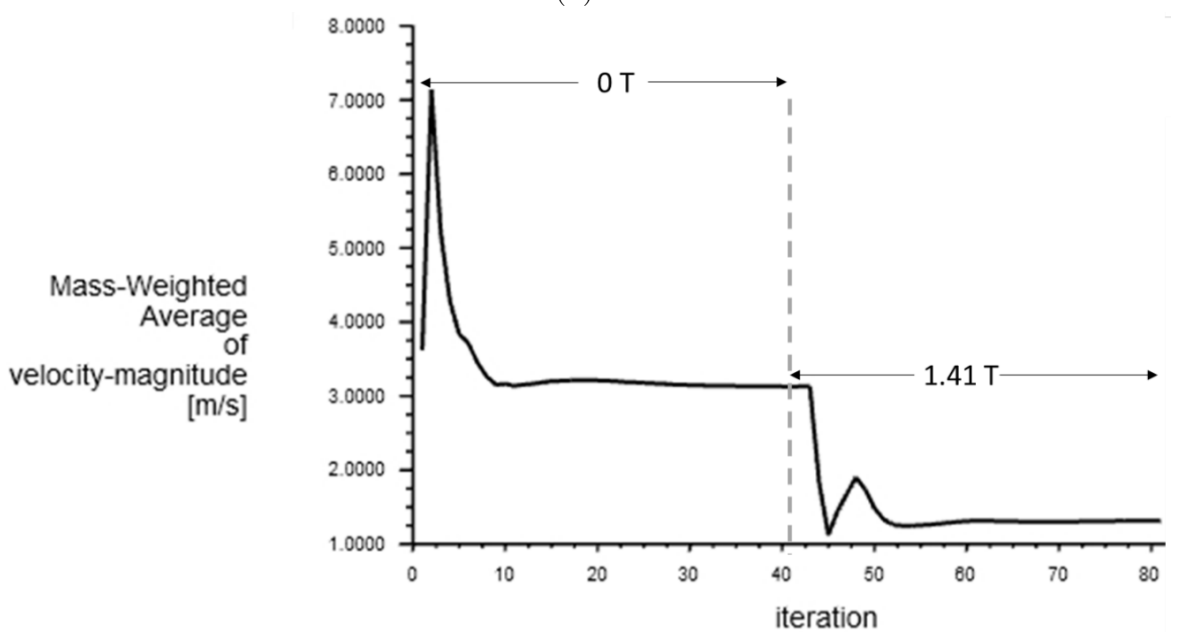

(c)

FIGURE 5. The mass-weighted average of velocity magnitude at the disk outlet under different magnetic fields: a. $0.5 \mathrm{~T}, \mathrm{~b} .1 \mathrm{~T}, \mathrm{c} .1 .41 \mathrm{~T}$. 


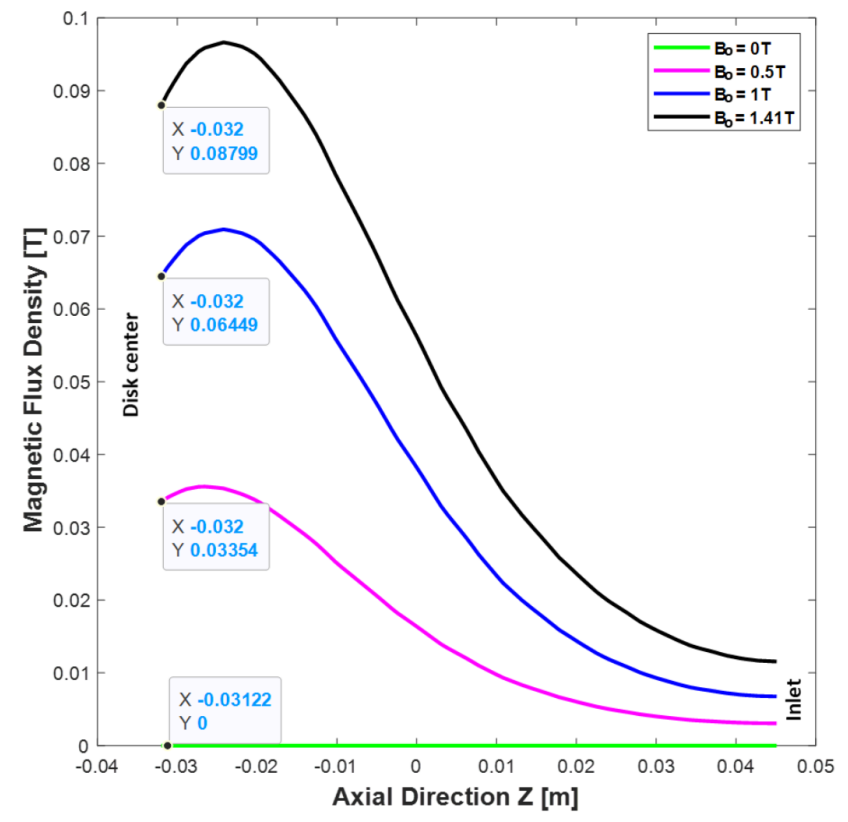

(A).

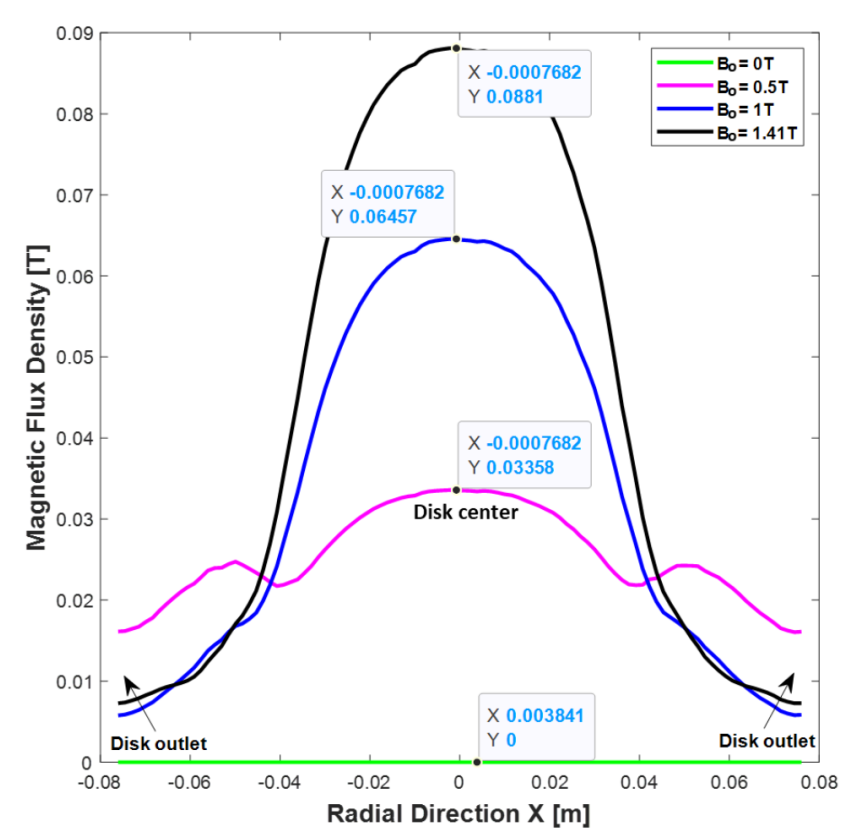

(B).

Figure 6. Plot of magnetic flux density along the nozzle pipe and disk channel: $6 \mathrm{a} .(0,0, z), 6 \mathrm{~b} .(x, 0,-0.032 \mathrm{~m})$.

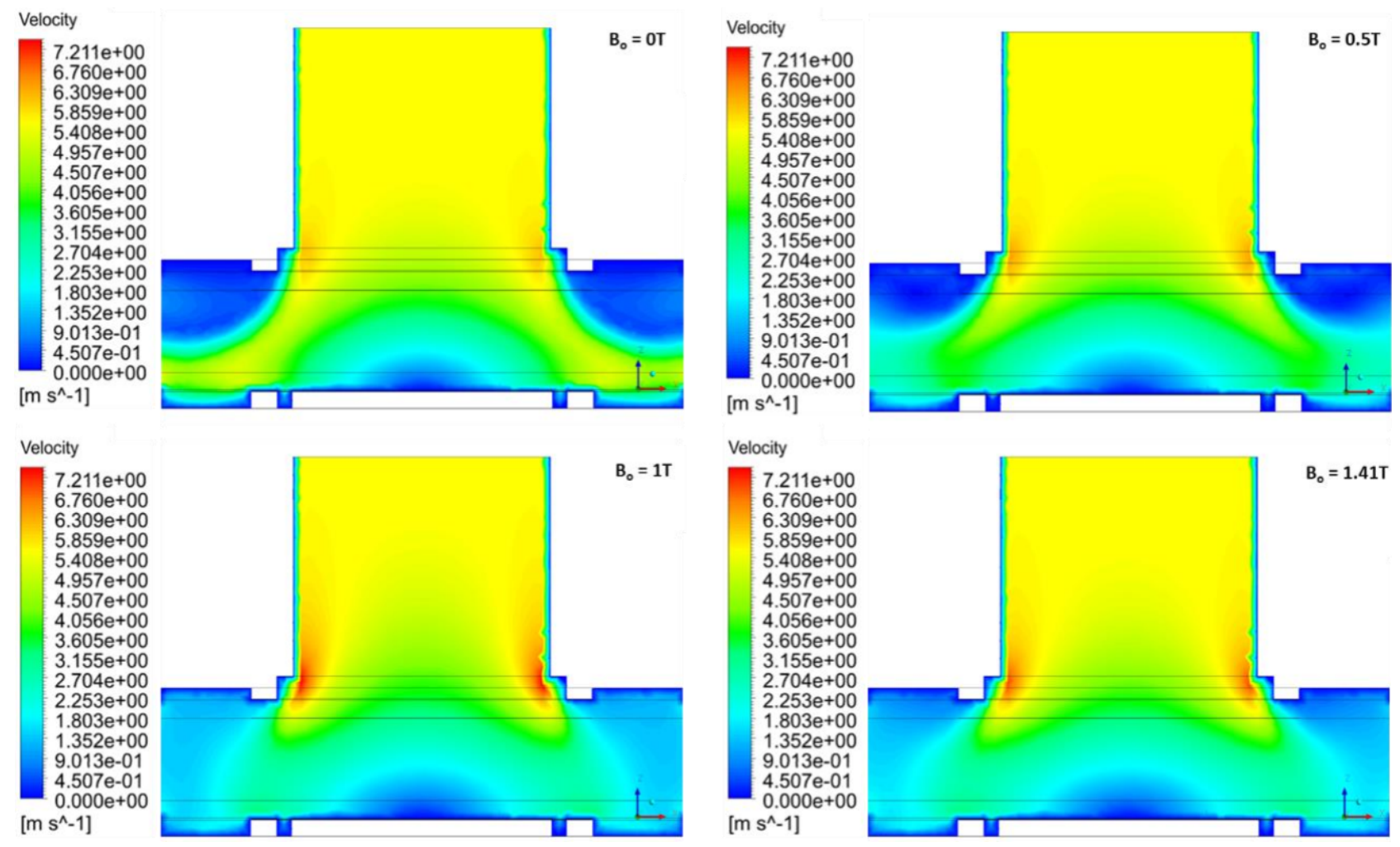

Figure 7. Contour of velocity magnitude along the nozzle pipe and disk channel $(x-z$ plane, $y=0)$. 


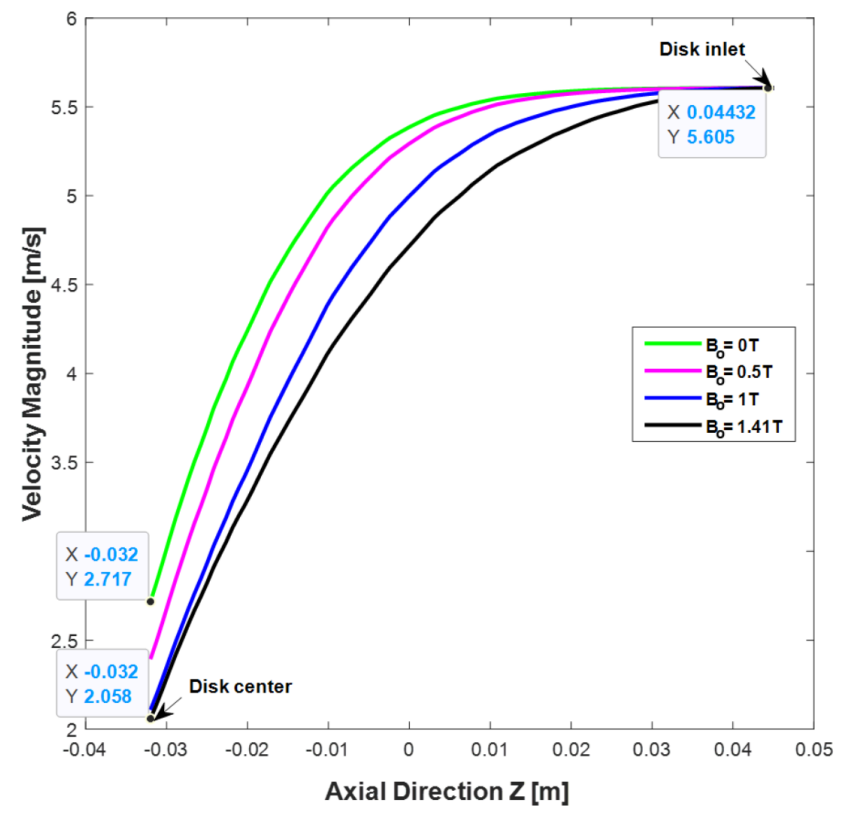

(A).

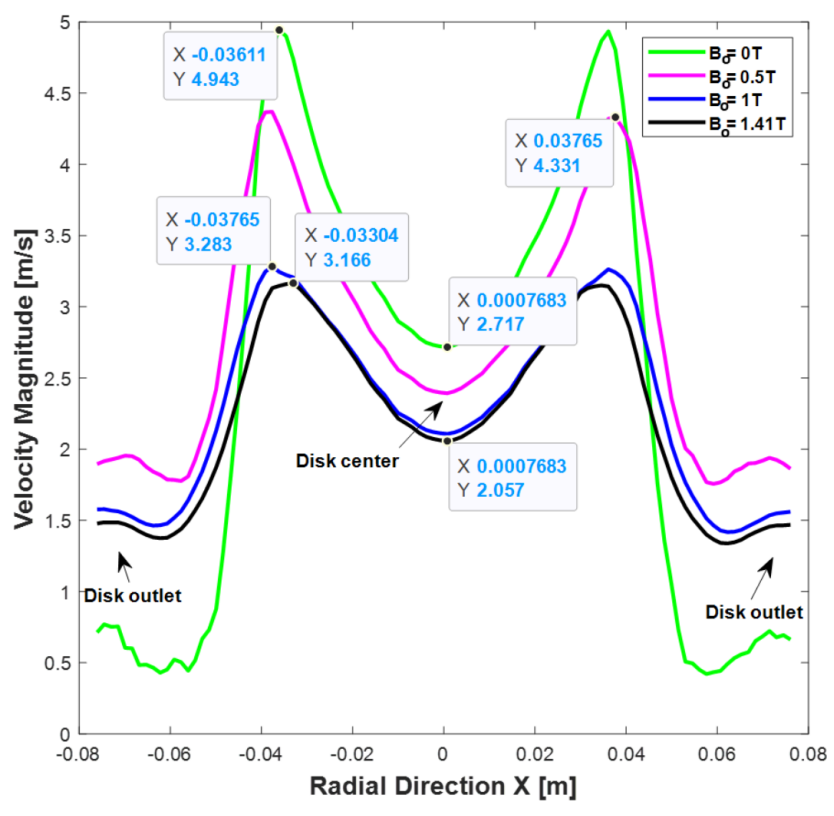

(B).

Figure 8. Plot of velocity distribution along the nozzle pipe and disk channel: $8 \mathrm{a} .(0,0, z), 8 \mathrm{~b} .(x, 0,-0.032 \mathrm{~m})$.

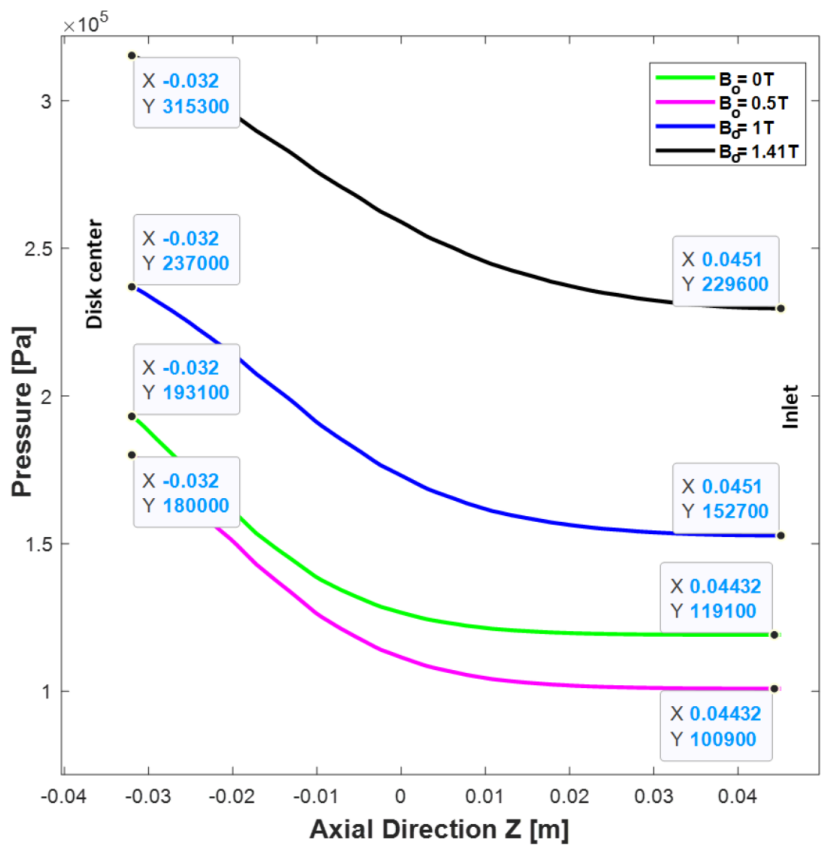

(A).

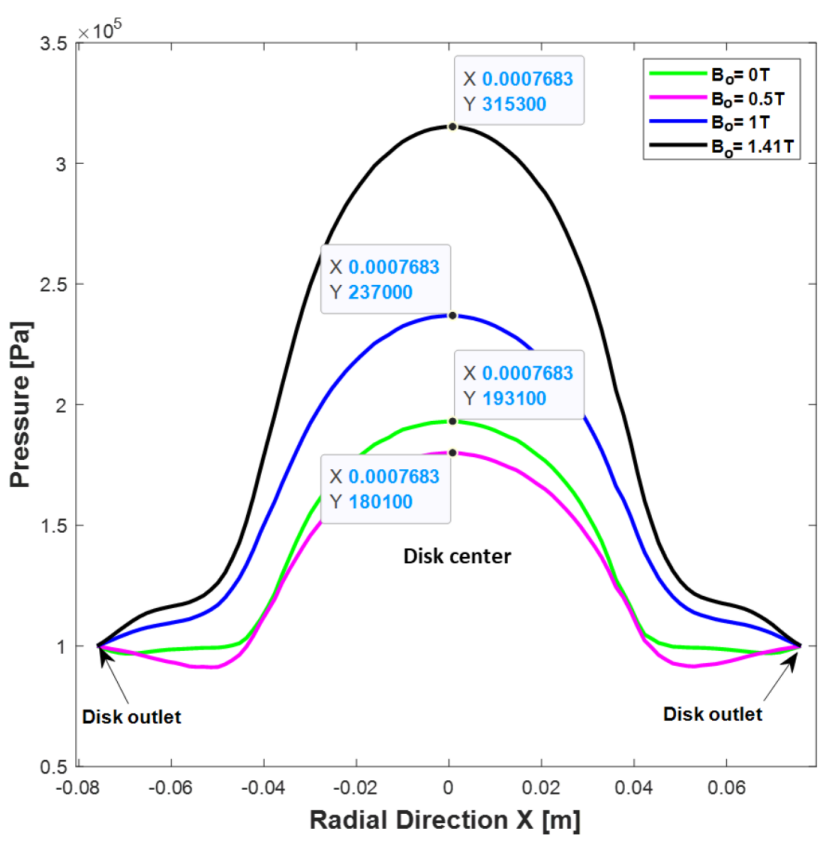

(B).

Figure 9. Plot of pressure distribution along the nozzle pipe and disk channel: 9a. $(0,0, z), 9 \mathrm{~b} .(x, 0,-0.032 \mathrm{~m})$. 


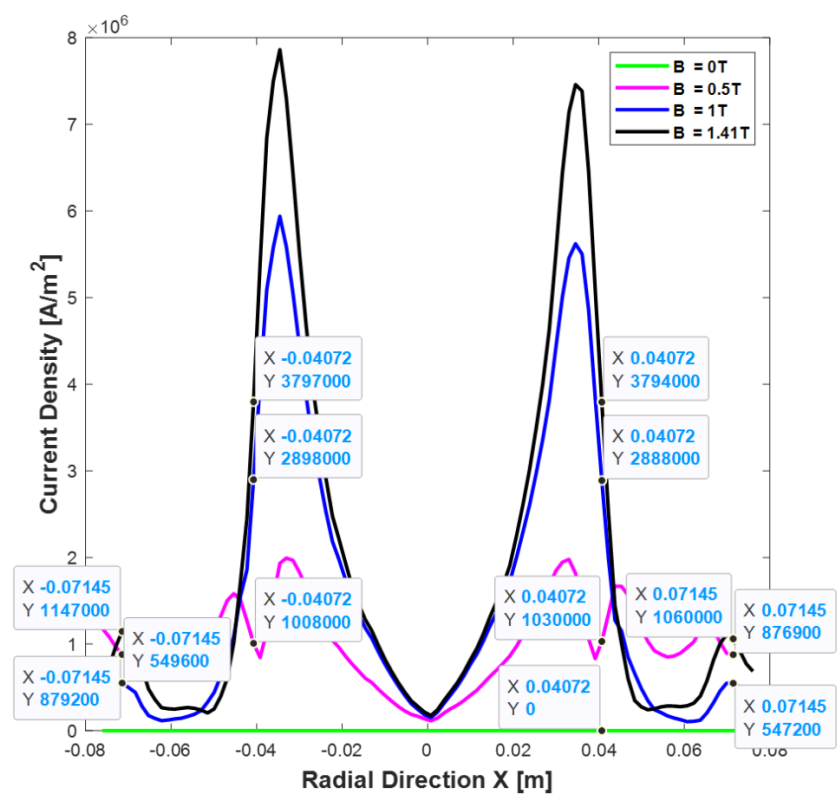

Figure 10. Plot showing the current density distribution along the inner and outer electrode regions: $(x, 0,-0.0224)$.
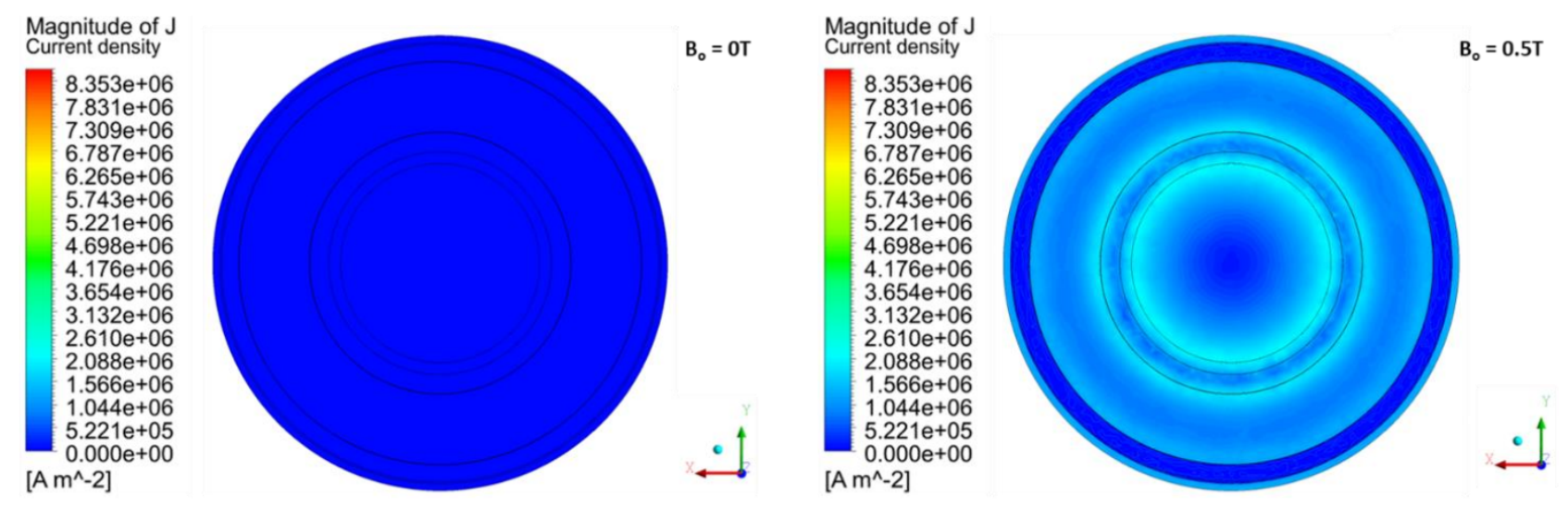

Magnitude of $\mathrm{J}$
Current density
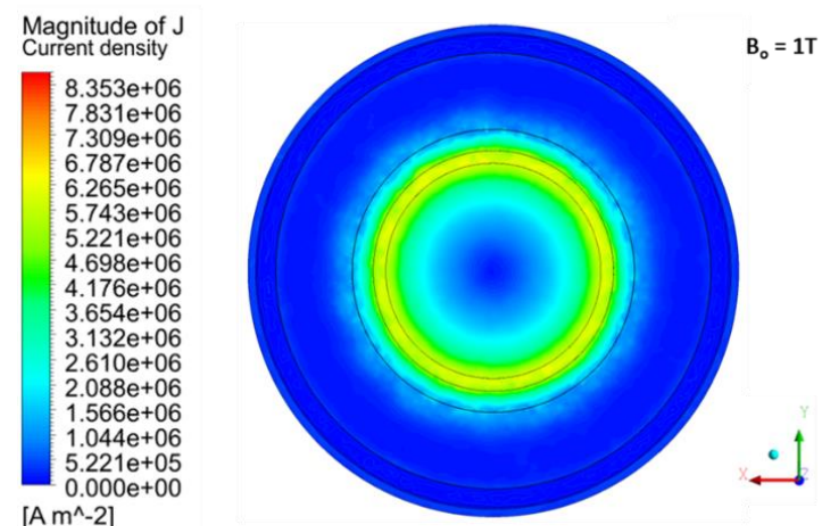

Magnitude of $\mathrm{J}$ Current density

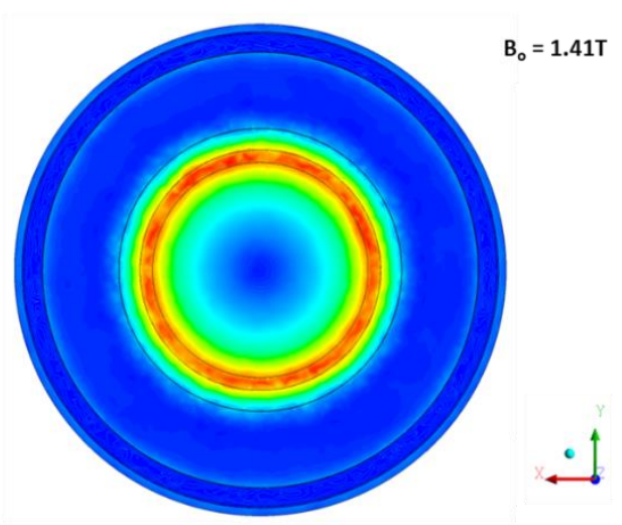

Figure 11. Contour showing the current density distribution along the inner and outer electrode regions $(x-y$ plane, $z=0)$. 


\begin{tabular}{|c|c|c|c|c|c|c|c|}
\hline & $\begin{array}{c}\text { Disk inlet } \\
\text { area }\end{array}$ & $\begin{array}{l}\text { Magnetic } \\
\text { fields }\end{array}$ & $\begin{array}{l}\text { Flow } \\
\text { rate }\end{array}$ & $\begin{array}{l}\text { Reynolds } \\
\text { number }\end{array}$ & $\begin{array}{l}\text { Hartmann } \\
\text { number }\end{array}$ & $\begin{array}{l}\text { Interaction } \\
\text { parameter }\end{array}$ & $\begin{array}{l}\text { Current } \\
\text { density }\end{array}$ \\
\hline & $\left(\mathrm{m}^{2}\right)$ & $\mathrm{B}_{0}(\mathrm{~T})$ & $Q\left(\mathrm{~m}^{3} / \mathrm{sec}\right)$ & $R_{e}$ & $H_{a}$ & $N$ & $j_{x}\left(\mathrm{~A} / \mathrm{m}^{2}\right)$ \\
\hline & & & $v A$ & $\left.v \rho D_{h}\right) / \mu$ & $\mathrm{B}_{0} D_{h} \sqrt{\sigma / \mu}$ & $\left(H_{a}\right)^{2} / R_{e}$ & $\operatorname{Max}$ \\
\hline Literature & 0.6540 & 0.3 & $0.18 \mathrm{e}-3$ & $\approx 4000$ & 140 & $\approx 5$ & $\approx 1 \mathrm{e} 5$ \\
\hline \multirow{4}{*}{ Present study } & 0.0185 & 0 & 0.1038 & $\approx 2.44 \mathrm{e} 6$ & 0 & $\approx 0$ & 0 \\
\hline & 0.0185 & 0.5 & 0.1038 & $\approx 2.44 \mathrm{e} 6$ & 2937 & $\approx 4$ & $\approx 1.03 \mathrm{e} 6$ \\
\hline & 0.0185 & 1 & 0.1038 & $\approx 2.44 \mathrm{e} 6$ & 5874 & $\approx 14$ & $\approx 2.89 \mathrm{e} 6$ \\
\hline & 0.0185 & 1.41 & 0.1038 & $\approx 2.44 \mathrm{e} 6$ & 8282 & $\approx 28$ & $\approx 3.79 \mathrm{e} 6$ \\
\hline
\end{tabular}

TABLE 3. Summary of current densities from past and present studies.

of $1 \mathrm{~T}$ and $1.41 \mathrm{~T}$ are applied, the current densities observed at the inner electrode are significantly higher than when $\mathrm{B}_{0}$ values of $0 \mathrm{~T}$ and $0.5 \mathrm{~T}$ are applied. Based on these observations, we can deduce that the higher the fluid velocity near the electrode region, the stronger the $j_{x}$ and the retarding force are. Similar deductions have been reported by [27].

For validation purposes, the current densities from the past and present studies on liquid $G a_{68} \operatorname{In}_{20} \mathrm{Sn}_{12}$ are presented in Table 3 [28 31]. In this table, the $j_{x}$ values are almost of the same order of magnitude. The slight difference may be due to an increase in $H_{a}$ values. We can also see that at high $R_{e}$ and $H_{a}$ values, $N$ and $j_{x}$ values increase.

\section{Conclusion}

This study has investigated the flow of liquid $\mathrm{Ga}_{68} \mathrm{In}_{20} \mathrm{Sn}_{12}$ in a disk-shaped MHD channel under different cases of $\mathrm{B}_{0}$. The effects of high $R_{e}$ and $H_{a}$ on the flow stability in the low Prandtl number fluid $\left(P_{r}=0.028\right)$ have been discussed in detail, with the main conclusions as follows.

(1.) At high $R_{e}$, the fluid velocity decreases along the nozzle pipe and disk channel regardless of $\mathrm{B}_{0}$.

(2.) When $\mathrm{B}_{0}$ values of $1 \mathrm{~T}$ and $1.41 \mathrm{~T}$ are applied, the fluid velocity decreases and spreads within the disk channel and walls due to high $H_{a}$ values (5874 and 8282 ).

(3.) The pressure increases from the nozzle pipe inlet to the disk channel and decreases to the outlet for different $\mathrm{B}_{0}$ cases.

(4.) The induced current density in the radial direction, $j_{x}$ increases within the disk channel and near the inner electrode edge as $\mathrm{B}_{0}$ increases. Moreover, the $j_{x}$ obtained for $\mathrm{B}_{0}$ values of $1 \mathrm{~T}$ and $1.41 \mathrm{~T}$ cases are significantly higher than in other cases.

(5.) The liquid $\mathrm{Ga}_{68} \mathrm{In}_{20} \mathrm{Sn}_{12}$ does not stick to channels coated with anti-stiction layers (Plexiglas and Teflon) and superlyophobic structured surfaces.

(6.) The numerical analysis obtained in this study showed that the $\mathrm{B}_{0}$ value of either $1 \mathrm{~T}$ or $1.41 \mathrm{~T}$ is needed to achieve the required flow stability, current density, and output powers. The study also lays the groundwork for a future research on liquid metals and MHD systems.

\section{ACKNOWLEDGEMENTS}

The presented research was financially supported by Cape Peninsula University of Technology.

\section{LIST OF SYMBOLS}

$R_{e}$ Reynolds number [-]

$H_{a}$ Hartmann number [-]

B Magnetic flux density [T]

$\mathrm{B}_{0} \quad$ External magnetic field $[\mathrm{T}]$

$b$ Induced magnetic field [T]

$P$ Pressure $[\mathrm{Pa}]$

$E$ Electric field [N/C]

$v_{r}$ Radial velocity $[\mathrm{m} / \mathrm{s}]$

$v_{q}$ Tangential velocity $[\mathrm{m} / \mathrm{s}]$

$P_{r} \quad$ Prandtl number [-]

$R_{h}$ Dimensionless factor [-]

$Q \quad$ Flow rate $\left[\mathrm{m}^{3} / \mathrm{sec}\right]$

$N$ Interaction parameter [-]

$D_{h} \quad$ Characteristic diameter or length of the channel [mm]

$v$ Fluid velocity $[\mathrm{m} / \mathrm{s}]$

$j$ Current density $\left[\mathrm{A} / \mathrm{m}^{2}\right]$

$e \quad$ Electron charge $[\mathrm{C}]$

$m_{e}$ Electron mass $[\mathrm{kg}]$

$v_{e h}$ Average momentum transfer collision frequency for an electron (e) with a heavy particle (h)

$\mu_{m}$ Magnetic permeability $[\mathrm{h} / \mathrm{m}]$

$H \quad$ Maxwell's induction field $[\mathrm{A} / \mathrm{m}]$

$k$ Thermal conductivity $[\mathrm{W} /(\mathrm{m} \mathrm{K})]$

$c_{p} \quad$ Specific heat $[\mathrm{J} /(\mathrm{kg} \mathrm{K})]$

\section{Greek symbols}

$\alpha \quad$ Thermal diffusivity of the fluid $\left[\mathrm{W} \mathrm{m}^{2} / \mathrm{J}\right]$

$\nu \quad$ Kinematic viscosity of the fluid $\left[\mathrm{m}^{2} / \mathrm{s}\right]$

$\rho$ Density of the fluid $\left[\mathrm{kg} / \mathrm{m}^{3}\right]$

$\sigma \quad$ Electric conductivity $[\mathrm{S} / \mathrm{m}]$

$\eta \quad$ Dynamic viscosity $[\mathrm{kg} /(\mathrm{ms})]$

$\beta \quad$ Hall parameter $[-]$ 


\section{REFERENCES}

[1] F. Mebarek-Oudina, R. Bessaih, B. Mahanthesh, et al. Magneto-thermal-convection stability in an inclined cylindrical annulus filled with a molten metal. International Journal of Numerical Methods for Heat 8 Fluid Flow 31(4):1172 - 1189, 2020. https://doi.org/10.1108/HFF-05-2020-0321

[2] S. Marzougui, M. Bouabid, F. Mebarek-Oudina, et al. A computational analysis of heat transport irreversibility phenomenon in a magnetized porous channel. International Journal of Numerical Methods for Heat \& Fluid Flow 2020. https://doi.org/10.1108/HFF-07-2020-0418

[3] A. Zaim, A. Aissa, F. Mebarek-Oudina, et al. Galerkin finite element analysis of magneto-hydrodynamic natural convection of $\mathrm{Cu}$-water nanoliquid in a baffled U-shaped enclosure. Propulsion and Power Research 9(4):383 393, 2020. https://doi.org/10.1016/j.jppr.2020.10.002.

[4] F. Mebarek-Oudina, O. D. Makinde. Numerical simulation of oscillatory MHD natural convection in cylindrical annulus: Prandtl number effect. Defect and Diffusion Forum 387:417 - 427, 2018. https://doi.org/10.4028/www.scientific.net/ddf.387.417

[5] A. O. Ayeleso, M. T. E. Kahn. Modelling of a combustible ionised gas in thermal power plants using MHD conversion system in South Africa. Journal of King Saud University - Science 30(3):367 - 374, 2018. https://doi.org/10.1016/j.jksus.2017.01.007.

[6] M. I. Hasan, A. J. F. Ali, R. S. Tufah. Numerical study of the effect of channel geometry on the performance of magnetohydrodynamic micro pump. Engineering science and technology, an international journal 20(3):982 989, 2017. https://doi.org/10.1016/j.jestch.2017.01.008.

[7] Y.-N. Wang, L.-M. Fu. CMicropumps and biomedical applications - A review. Microelectronic Engineering 195:121 - 138, 2018. https://doi.org/10.1016/j.mee.2018.04.008

[8] A. O. Ayeleso, M. T. E. Kahn, A. K. Raji. Plasma energy conversion system for electric power generation. In 12th International Conference on the Industrial and Commercial Use of Energy, pp. 206 - 211. Cape Town, South Africa.

[9] L. Li, H.-l. Huang, G.-p. Zhu. Numerical Simulations for a Partial Disk MHD Generator Performance. Energies 11(1):127, 2018. https://doi.org/10.3390/en11010127

[10] H. Teimouri, M. Afrand, N. Sina, et al. Natural convection of liquid metal in a horizontal cylindrical annulus under radial magnetic field. International Journal of Applied Electromagnetics and Mechanics 49(4):453 - 461, 2015. https://doi.org/10.3233/JAE-150028.

[11] M. Afrand, S. Farahat, A. H. Nezhad, et al. 3-D numerical investigation of natural convection in a tilted cylindrical annulus containing molten potassium and controlling it using various magnetic fields. International Journal of Applied Electromagnetics and Mechanics 46(4):809 - 821, 2014. https://doi.org/10.3233/JAE-141975.
[12] S. L. Yadav, D. Kumar, A. K. Singh.

Magnetohydrodynamic flow in horizontal concentric cylinders. International Journal of Industrial Mathematics 11(2):89 - 98, 2019.

[13] X.-D. Zhang, X.-H. Yang, Y.-X. Zhou, et al. Experimental investigation of galinstan based minichannel cooling for high heat flux and large heat power thermal management. Energy conversion and management 185:248 - 258, 2019. https://doi.org/10.1016/j.enconman.2019.02.010.

[14] M. H. Taheri, N. Askari, M. H. Mahdavi. Prediction of entrance length for magnetohydrodynamics channels flow using numerical simulation and artificial neural network. Journal of Applied and Computational Mechanics 6(3):582 - 592, 2020. https://doi.org/10.22055/jacm.2019.29201.1571

[15] Z. Li, J. Li, X. Li, M.-J. Ni. Free surface flow and heat transfer characteristics of liquid metal galinstan at low flow velocity. Experimental Thermal and Fluid Science 82:240 - 248, 2017. https://doi.org/10.1016/j.expthermflusci.2016.11.021.

[16] A. Hirsch, L. Dejace, H. O. Michaud, S. P. Lacour. Harnessing the rheological properties of liquid metals to shape soft electronic conductors for wearable applications. Accounts of chemical research 52(3):534 - 544, 2019. https://doi.org/10.1021/acs.accounts.8b00489

[17] J. Touronen, M. Männistö, D. Richon, et al. Application of GaInSn Liquid Metal Alloy Replacing Mercury in a Phase Equilibrium Cell: Vapor Pressures of Toluene, Hexylbenzene, and 2-Ethylnaphthalene. Journal of Chemical \& Engineering Data 65(7):3270 3276, 2020. https://doi.org/10.1021/acs.jced.9b01208.

[18] S. S. Kadlaskar, J. H. Yoo, J. B. Lee, W. Choi. Costeffective surface modification for galinstan ${ }^{\circledR}$ lyophobicity. Journal of colloid and interface science 492:33 - 40, 2017.

[19] M. H. Avnaim, B. Mikhailovich, A. Azulay, A. Levy. Numerical and experimental study of the traveling magnetic field effect on the horizontal solidification in a rectangular cavity part 1: Liquid metal flow under the TMF impact. International Journal of Heat and Fluid Flow 69:23 - 32, 2018. https://doi.org/10.1016/j.ijheatfluidflow.2017.11.003

[20] M. H. Avnaim, B. Mikhailovich, A. Azulay, A. Levy. Numerical and experimental study of the traveling magnetic field effect on the horizontal solidification in a rectangular cavity part 2: Acting forces ratio and solidification parameters. International Journal of Heat and Fluid Flow 69:9 - 22, 2018. https://doi.org/10.1016/j.ijheatfluidflow.2017.11.004

[21] A. Altintas, I. Ozkol. Magnetohydrodynamic flow of liquid-metal in circular pipes for externally heated and non-heated cases. Journal of applied fluid mechanics 8:507 - 514, 2015. https://doi.org/10.18869/acadpub.jafm.67.222.22862

[22] M. Gallo, H. Nemati, B. J. Boersma, et al. "Magnetic-ribs" in fully developed laminar liquid-metal channel flow. International Journal of Heat and Fluid Flow 56:198 - 208, 2015. https://doi.org/10.1016/j.ijheatfluidflow.2015.07.010 
[23] C. Kratzsch. Liquid Metal Flow in Continuous Casting Molds: A Numerical Approach on Electromagnetic Flow Control, Turbulence and Multiphase Phenomena. Ph.D. thesis, Technische Universität Bergakademie Freiberg, 2018. https://doi.org/10.13140/RG.2.2.21872.92168

[24] S. Mahjabin, M. A. Alim. Effect of Hartmann number on free convective flow of MHD fluid in a square cavity with a heated cone of different orientation. American Journal of Computational Mathematics 8(4):314 - 325, 2018. https://doi.org/10.4236/ajcm.2018.84025

[25] N. Kanaris, X. Albets, D. Grigoriadis, S. Kassinos. Three-dimensional numerical simulations of magnetohydrodynamic flow around a confined circular cylinder under low, moderate, and strong magnetic fields. Physics of Fluids 25(7):074102, 2013. https://doi.org/10.1063/1.4811398

[26] M. H. Taheri, M. Abbasi, M. Khaki Jamei. Development length of laminar magnetohydrodynamics pipe flows. Journal of Computational \& Applied Research in Mechanical Engineering 9(2):397 - 407, 2020. https://doi.org/10.22061/jcarme.2019.4416.1533

[27] O. D. Makinde, O. O. Onyejekwe. A numerical study of MHD generalized Couette flow and heat transfer with variable viscosity and electrical conductivity. Journal of Magnetism and Magnetic Materials 323(22):2757 - 2763, 2011. https://doi.org/10.1016/j.jmmm.2011.05.040
[28] N. B. Morley, S. Smolentsev, R. Munipalli, et al. Progress on the modeling of liquid metal, free surface, MHD flows for fusion liquid walls. Fusion Engineering and Design 72(1 - 3):3 - 34, 2004. https://doi.org/10.1016/j.fusengdes.2004.07.013.

[29] D. Jian, C. Karcher. Flow rate measurements in turbulent liquid metal channel flow using Time-of-Flight Lorentz force velocimetry. Proceedings in Applied Mathematics and Mechanics 12(1):577 - 578, 2012. https://doi.org/10.1002/pamm.201210277

[30] D. Jian, C. Karcher. Electromagnetic flow measurements in liquid metals using time-of-flight Lorentz force velocimetry. Measurement science and technology 23(7):074021, 2012. https://doi.org/10.1088/0957-0233/23/7/074021.

[31] M. Modestov, E. Kolemen, A. E. Fisher, M. G. Hvasta. Electromagnetic control of heat transport within a rectangular channel filled with flowing liquid metal. Nuclear Fusion 58(1):016009, 2017. https://doi.org/10.1088/1741-4326/aa8bf4. 